\title{
DOSSIÊ TEMÁTICO: Vicissitudes de uma década
}

É com muita satisfação que apresentamos o Dossiê comemorativo aos dez anos da Revista Êxitus. Na classificação de bodas e jubileus, dez anos remete ao estanho, elemento químico classificado como um metal maleável e resistente que, ao formar ligações químicas pode tanto doar quanto receber elétrons para atingir a estabilidade.

Tendo seu primeiro número publicado em 2011, a Revista Exitus, a exemplo do estanho, recebe força das políticas de fortalecimento da Universidade pública, materializadas na criação da Universidade Federal do Oeste do Pará - UFOPA, em 2009, e também confere força ao movimento de criação do Programa de Pós-Graduação em Educação desta Universidade, efetivado em 2013.

Maleabilidade e resistência são características apropriadas para definir a revista Êxitus, cujo cenário progressista de criação se reverte nos anos seguintes por influência de movimentos radicais conservadores que ameaçam qualquer forma de organização e avanço da ciência no Brasil. Nessa conjuntura, a resistência da Revista Êxitus se expressa pela interlocução que estabelece com pesquisadores/as em nível nacional e internacional, expandindo suas bases de indexação para a América Latina e a Europa.

Fazer parte desse momento comemorativo muito nos orgulha! Para a organização deste dossiê nos orientamos pela premissa dos dez anos, com vistas a apresentar contribuições originárias de pesquisadores de diversas regiões do país e do exterior, acerca das políticas educacionais na última década.

César Nunes abre o Dossiê com a sistematização de Conferência "Estado, Economia e Educação no Brasil: matrizes histórico-políticas dos projetos atuais em disputa, a Pedagogia das Competências e Habilidades versus a Pedagogia do Direito à Educação e dos Direitos de Aprendizagem", realizada em comemoração dos 10 anos da Revista Êxitus. O autor relata uma pesquisa qualitativa de natureza bibliográfico-histórica sobre as matrizes epistemológicas e políticas da Educação Brasileira para caracterizar as duas políticas públicas de Educação que engendradas pós Constituição Federal de 1988; de um lado a Pedagogia das Competências e Habilidades, de inspiração neoliberal, com dispositivos avaliativistas e bonificadores, com a articulação da Educação aos interesses do mercado de trabalho global e seus constructos identitários e, de outro lado aponta as características da 
Pedagogia do Direito à Educação e dos Direitos de Aprendizagem. Decorrente dessa clivagem histórico-política aponta possibilidades para a interpretação das políticas de formação de professores nessa etapa republicana recente.

O artigo intitulado "Monitoramento e avaliação dos planos decenais de educação dos municípios da zona da mata mineira", de autoria de Rosangela dos Santos e Elisangela Alves da Silva Scaff, tem como objetivo analisar como se evidencia a participação da sociedade civil no monitoramento e avaliação dos Planos Decenais de Educação dos municípios da Zona da Mata Mineira. O estudo aponta a expressiva redução de relatórios de monitoramento e avaliação, em comparação a quantidade de planos elaborados pelos municípios, evidenciando também a escassa participação de instâncias da sociedade civil, entre as quais se destaca o Conselho Municipal de Educação, com maior participação nos relatórios elaborados. As autoras defendem que compreender o movimento da realidade local frente às mudanças estruturais na configuração do Estado brasileiro e, nessa conjuntura, o afrouxamento dos princípios democráticoparticipativos conquistados na Constituição Federal de 1988, torna-se elemento imprescindível para a análise desse momento histórico.

No texto "Notas sobre política de ensino técnico superior no Chile: progresso e desafios 2010-2020", Jorge Alacón Leiva e Catalina Gotelli-Alvial examinam alguns aspectos da Educação Superior Técnica no Chile. Como resultado dessa análise, apresentam alguns desafios que se colocam ao Ensino Superior Técnico no país, como a crescente inclinação ao mercado, mas com a definição de currículos realizada por políticas públicas de financiamento, cuja orientação se apoia na formação baseada em competências, o que imprime uma distinção entre a formação técnica e a formação superior.

O artigo intitulado "A Política Educacional na década 2010 a 2020: análise de publicações", de autoria de Jefferson Mainardes e Silvana Stremell, se debruça sobre as principais temáticas abordadas em dossiês e seções temáticas de periódicos brasileiros, no período de 2010 a 2020, indicando temáticas presentes e ausentes, bem como comparações com temáticas abordadas em periódicos de língua inglesa. Identifica, na produção dos periódicos brasileiros, a relevância atribuída a temáticas cruciais da Política Educacional da década de 2010 a 2020, incluindo questões e problemas da conjuntura atual.

Maria Alice de Miranda Aranda, Giselle Cristina Martins Real e Fabio Perboni apresentam o artigo "Educação básica em contextos assimétricos no Brasil de 2010 a 2020: política e gestão como objeto de pesquisa da pósgraduação", com o objetivo de revelar temas que têm se constituído como 
objeto de estudo do Programa de Pós-Graduação em Educação da Universidade Federal da Grande Dourados (PPGEdu/UFGD) no campo das políticas e da gestão para a educação básica, entre 2010 e 2020. O texto identifica um conjunto de desafios para a pesquisa educacional, na perspectiva da política e da gestão, com a notificação das problemáticas presentes na educação básica, foco das pesquisas educacionais nesses espaços.

Em "Contornos da gestão escolar no Brasil", Cristiane Machado e Maria Helena Bravo exploram as respostas dos questionários contextuais dos diretores nas aferições de 2007 e 2015 da Prova Brasil com o objetivo de traçar os contornos do perfil dos diretores e analisar as práticas de gestão escolar democrática por eles declaradas. Os resultados do estudo apontam para um perfil do gestor escolar brasileiro majoritariamente do sexo feminino (80\%), com ensino superior (94,08\%), formado há mais de 8 anos $(77,5 \%)$ e com especialização (74,5\%). Sobre a gestão democrática os dados demonstram que, em 2015, 8\% das escolas públicas, aproximadamente 4.455 estabelecimentos, não existia Conselho Escolar e 2,51\% (1.398) das escolas não tinham Projeto Político Pedagógico.

Sinara Almeida da Costa e Rosimeire Costa de Andrade Cruz em "O balanço de uma década da promulgação das diretrizes curriculares nacionais para a educação infantil", apresentam um balanço do que foi produzido em trabalhos científicos na área de Educação Infantil na primeira década após a promulgação das Diretrizes Curriculares Nacionais para a Educação Infantil - DCNEl (BRASIL, 2009). Como resultados apontam os temas de maior destaque nas pesquisas e que envolvem a compreensão de currículo em sua episteme, perpassando por reflexões acerca das teorias, concepções e conceitos que o compõem e demonstram que assuntos como o brincar, as interações, a educação para as relações étnico-raciais, a avaliação e a prática com bebês, fundamentais para a efetivação de um currículo que considere a criança como centro, ainda são pouco explorados ou sequer aparecem entre os temas focalizados.

Por fim, em "Um novo ethos educacional no ensino médio: da formação integral ao empreendedorismo", Marilda de Oliveira Costa e Raquel Maria Caetano analisam a emergência do empreendedorismo como um eixo central na formação das juventudes, adotado em reformas educacionais para o ensino médio em dois estados da federação - Mato Grosso e Rio Grande do Sul, orientadas pela Base Nacional Comum Curricular (BNCC) e Novo Ensino Médio. Concluem que as recentes legislações relativas a políticas de empreendedorismo estaduais alteram projeto de educação pública e acenam para um novo ethos educacional, 
voltado para atender a lógica do desemprego, da precarização, da robotização e uberização do trabalho na era do capital improdutivo.

Desejamos boa leitura e excelentes reflexões individuais e coletivas!

Organizadoras:

Profa. Dra. Cristiane Machado Universidade Estadual de Campinas - UNICAMP Orcid iD: http://orcid.org/0000-0002-3522-4018 crimacha@unicamp.br

Profa. Dra. Elisangela Scaff Universidade Federal do Paraná - UFPR Orcid iD: https://orcid.org/0000-0002-7682-0879

elisscaff@gmail.com 